\title{
Neuroendocrine neoplasms of the digestive system - current classification and terminology
}

\author{
Agata Bałdys-Waligórska', Andrzej Nowak² \\ 'Department of Endocrinology and Internal Medicine, Faculty of Medicine and Health Sciences, Andrzej Frycz Modrzewski Krakow University, \\ Krakow, Poland \\ ${ }^{2}$ The University Hospital in Krakow, Krakow, Poland
}

The system of classification and terminology of neuroendocrine neoplasms (NENs), updated in 2017 by AJCC and in 2019 by $\mathrm{WHO}$, is now recommended for general use. This article is a review of this classification with respect to NENs of the digestive tract. Within the new system, two categories of neuroendocrine neoplasms of the digestive system were introduced, differing in morphology, clinical course and treatment, as based on differentiation and histological maturity grading (G). Among NENs of the digestive tract, well differentiated neuroendocrine tumours, with Ki-67 proliferation index below 20\%, NET G1 and NET G2, histologically resembling normal neuroendocrine cells were distinguished. Neuroendocrine neoplasms with Ki-67 above 20\% - termed neuroendocrine carcinoma NEC (poorly differentiated carcinoma G3) - were found to be heterogeneous. In every organ of the digestive tract a limited group of well differentiated tumours with Ki-67 above 20\%, but typically less than 55\% (well differentiated high grade NET G3) was distinguished. The remaining poorly differentiated neuroendocrine neoplasms with Ki-67 above 20\%, usually over 55\%, were classified as NEC (high grade neuroendocrine carcinoma). Within NEC, two groups were distinguished - large cell and small cell carcinomas. By introducing this new classification based on clinical and molecular research, any confusion between NET G3 and NEC is avoided. NEC, goblet-cell carcinoid of the appendix and MiNEN, which should be classified according to criteria applied to adenocarcinomas of their respective organs of the digestive system, are not discussed.

Key words: neuroendocrine neoplasms, NET, NEC, G grading system, TNM classification, staging

\section{Introduction}

Neuroendocrine neoplasms (NENs) are rare neoplasms found throughout the body. They originate from endocrine organs, the nervous system (peptidergic neurons) or from neuroendocrine cells of the diffuse endocrine system (DES). Here, only NENs present in the gut and pancreas will be discussed.

According to recent epidemiology studies in the US, based on The Surveillance, Epidemiology and End Results (SEER) programme [1], there is an increase in NEN incidence. Currently, the yearly incidence of these neoplasms is estimated at about 35 cases per 100000 individuals. Of these, about 70\% are gastroenteropancreatic neuroendocrine neoplasms (GEP
NENs), constituting only $2 \%$ of all neoplasms of the digestive system $[2,3]$. With respect to their embryonic development, NENs of the digestive system are classified as those of the foregut (i.e. from the oropharynx to the upper duodenum, liver, gallbladder, pancreas), the midgut (middle part of the duodenum to the right two-thirds of the transverse colon) and the hindgut (the left one-third of the transverse colon including the upper anal canal) [4].

\section{Histopathological classification of NENs}

In its Neuroendocrine Neoplasm/Neuroendocrine Tumour (NEN/NET) classification system, the European Neuroendocrine 
Tumour Society (ENETS) considers the type of cell, organ location and histological type including differentiation. According to ENETS, the histological maturity of the tumour ( $G$ - grading) is of main clinical significance [5]. The pTNM classification of the tumour [6] and clinical advancement staging (S) [5] need also to be considered.

The histological tumour maturity grading $(\mathrm{G})$ is a microscopic feature of prognostic value in treating NENs of the digestive system. It is an independent predictive parameter of clinical outcome for patients with low (G1), intermediate (G2) or high (G3) NEN malignancy.[7-11]. The criteria for determining the histological malignancy grading of NENs based on mitotic and Ki-67 proliferation indices are presented in table I [3].

The mitotic index is the number of mitotic figures in hot spots counted in no less than ten HPFs (high power fields, $2 \mathrm{~mm}^{2}$ ) at $40 \mathrm{x}$ magnification. The Ki-67 proliferation index is evaluated by immunocytochemistry (ICH) with MIB1 antibody as the percentage of cells presenting a positive reaction, counted in 500-2000 tumour cells. Selection of the higher value of these two indices is recommended as the G grade. NEN classification systems and therapeutic decisions rely on the $\mathrm{G}$ grade, as based on those two indices [3, 6, 12-14].

The grading system developed by ENETS for all NETs arising in the pancreas and gastrointestinal tract was adopted by the World Health Organization (WHO) in 2010. Within this system, two categories of neuroendocrine neoplasms of the digestive system were introduced, differing in morphology, clinical course and treatment, as based on differentiation and histological maturity grading $(G)[15]$. The first category consisted of well differentiated neoplasms (termed carcinoids prior to the year 2000), the Ki-67 proliferation index of which ranges between 0-20\%, NET G1 and NET G2 (well differentiated neuroendocrine tumours: G1, G2). Histologically, NET G1 and NET G2 cells resemble normal neuroendocrine cells, expressing neuroen- docrine markers (synaptophysin and chromogranin A [CgA]) and site-dependent hormones, low or medium nuclear atypia, and no more than 20 mitotic figures per 10 HPFs. Tumours classified as NET G1 or NET G2 should be treated according to standards pertaining to well differentiated neuroendocrine tumours [3,16-18]. Within the 2010 WHO classification, the second category included neuroendocrine neoplasms with a Ki-67 proliferation index above 20\%, termed neuroendocrine carcinoma NEC (poorly differentiated carcinoma G3). According to the 2017 Eighth Edition of the American Joint Committee on Cancer (AJCC) [11] and the new 2019 WHO Classification of Digestive System Tumours (presented in the $5^{\text {th }}$ edition of the WHO Classification of Tumours series [13]), the group of poorly differentiated neuroendocrine neoplasms G3 was found to be heterogeneous [7,19]. In every organ of the digestive system a limited group of well differentiated tumours with Ki-67 proliferation index above 20\%, typically ranging between 21 and 55\% (well differentiated high grade NET G3) was distinguished [9, 10, 13, 20-24]. Unlike in the case of NET G3, the remaining poorly differentiated neuroendocrine neoplasms with Ki-67 proliferation index above 20\%, usually over 55\%, were classified as NECs (high grade neuroendocrine carcinoma). Within NEC, two groups were distinguished - large cell or small cell carcinomas, the course of the latter resembling that of aggressive small cell lung cancer. NEC strongly express synaptophysin and weakly express chromogranin A, demonstrate apparent nuclear atypia and over 20 mitotic figures per 10 HPFs. By introducing this new classification, based on clinical and molecular research, the confusion between NET G3 and NEC is avoided [13]. The currently proposed classification of NENs, which includes 2017 AJCC and 2019 WHO recommendations, is presented in table II.

Mixed neoplasms with exo- and endocrine components, earlier classified as mixed adenoneuroendocrine carcinoma

Table I. Grading criteria for assessing malignancy of neuroendocrine neoplasms $[3,11]$

\begin{tabular}{lcc}
$\begin{array}{l}\text { Histological malignancy grade of NEN } \\
\text { (G) }\end{array}$ & $\begin{array}{c}\text { Mitotic activity/no. of mitotic } \\
\text { figures/10 HPF }\end{array}$ & $\begin{array}{c}\text { Ki-67 proliferation index/\% of cells (per } \\
\mathbf{2 , 0 0 0} \text { cells) }\end{array}$ \\
\hline G1 - well differentiated, low grade & $<2$ & $<3$ \\
\hline G2 - moderately differentiated, intermediate grade & $2-20$ & $3-20$ \\
G3 - poorly differentiated, high grade & $>20$ & $>20$
\end{tabular}

Table II. Neuroendocrine neoplasms grading according to WHO 2019 and AJCC 2017 [11, 13-14]

\begin{tabular}{|c|c|c|c|}
\hline \multicolumn{4}{|c|}{ Neuroendocrine neoplasm (NENs) } \\
\hline NET G1 & well-differentiated tumours & \multirow{2}{*}{ proliferation index $<20 \%$} & $\begin{array}{l}\text { well-differentiated tumours with } \mathrm{Ki}-67 \text { proliferation } \\
\text { index below } 3 \%\end{array}$ \\
\hline NET G2 & well-differentiated tumours & & $\begin{array}{l}\text { well-differentiated tumours with Ki- } 67 \text { proliferation } \\
\text { index from } 3 \% \text { to } 20 \%\end{array}$ \\
\hline NET G3 & well-differentiated tumours & \multirow{2}{*}{ proliferation index $>20 \%$} & $\begin{array}{l}\text { well-differentiated tumours with Ki-67 proliferation } \\
\text { index usually between } 21 \text { and 55\% }\end{array}$ \\
\hline NEC & $\begin{array}{l}\text { neuroendocrine cancers } \\
\text { poorly-differentiated }\end{array}$ & & $\begin{array}{l}\text { neuroendocrine cancers with proliferation index } \\
\text { above } 21 \% \text {, usually above } 55 \% \\
\text { - large-cell cancers } \\
\text { - small-cell cancers }\end{array}$ \\
\hline
\end{tabular}


(MANEC) [5, 15], are presently termed mixed neuroendocrine-non-neuroendocrine carcinoma (MiNEN) if both components are distinguishable, with each component to be graded individually $[13,25]$.

NEC, goblet-cell carcinoid of the appendix and MiNENs should be classified according to classical criteria applied to adenocarcinomas of organs of the digestive system, and are not discussed here.

\section{Genetics}

Current knowledge of genetics and molecular differences between different types of NENs stimulated a meeting of experts at the International Agency for Research on Cancer (IARC) in November 2017. A consensus was proposed to distinguish between well differentiated neuroendocrine tumours (NETs) and poorly differentiated neuroendocrine carcinomas (NECs) at all sites where these neoplasms arise, as based on differences in their molecular structure [8]. Mutations in MEN1, DAXX and ATRX are found in well-differentiated NETs, while NECs usually carry TP53 or RB1 mutations [26]. The 2017 IARC consensus has been incorporated in the $2019 \mathrm{WHO} 5^{\text {th }}$ Edition of classification of neuroendocrine neoplasms [20].

\section{Neuroendocrine tumours of the stomach (gastric NETs)}

Within the gastric NET group, the 2017 AJCC staging system includes gastric "carcinoid" tumours (NET G1 and G2, and rare well-differentiated G3). High-grade neuroendocrine carcinoma (NEC) and mixed adenoneuroendocrine carcinoma MiNEN) are staged according to the classification of stomach adenocarcinomas.

The following changes were introduced in the 2017 AJCC staging system: stage Groups I-IV were condensed, i.e. substages $A$ and $B$ were excluded; gastrin was added as an additional recommended clinical care factor; pancreastatin was added as an emerging prognostic factor of clinical care [9]. Over the years 1975-2014, the yearly incidence of gastric neuroendocrine tumours has increased from 0.31 to 4.85 per 100000 individuals [27]. This most likely results from the availability of more sophisticated methods and diagnostic tools in endoscopy, laboratory tests or nuclear medicine.

Gastric NETs may develop from different cells: histamine-producing enterochromaffin-like (ECL) cell NETs located in the corpus/fundus, somatostatin-expressing D-cell and gastrin-expressing G-cell NETs located in the antrum, or rare enterochromaffin-cell NETs producing serotonin, located in the antrum and corpus/fundus. Measurements of gastric $\mathrm{pH}$, a-intrinsic factor or a-parietal cell antibody and gastrin levels are useful in differentiating between the three different types of gastric ECL NETs and in diagnosing type I, type II and type III gastric NET [11,13, 28-31].

Several prognostic factors may also be useful in diagnosing these three types of gastric NETs: gastrin is expected to be elevated in type I and type II gastric NETs [31], while gastrin is expected to remain within the normal range in type III gastric NETs.[13]. CgA is a general NET marker, however with known limitations [32]. Plasma or serum CgA is used as a marker in patients with gastric NETs. Higher CgA levels are associated with a worse prognosis [31]. Moreover, changes in the CgA level within follow up may be useful in the prognosis of recurrence after surgery or the response to therapy of metastatic disease patients [33].

\section{Type 1 gastric NET}

Type 1 gastric NETs, composed of ECL-cells are most common and typically occur as multiple small polyps in the corpus or fundus. These NETs are associated with autoimmune chronic atrophic gastritis, causing hypochlorhydria and leading to hypergastrinemia. Type 1 gastric NETs rarely metastasize. The 5 -year survival rate of patients is close to $100 \%$.

\section{Type 2 gastric NET}

Type 2 gastric NETs are rare ECL-cell tumours diagnosed in patients with multiple endocrine neoplasia type 1 (MEN1) presenting with multiple gastrinoma of the duodenum or pancreas, leading to secondary hypergastrinemia. These tumours exhibit a more aggressive phenotype with metastases in 10-30\% of cases. The 5-year survival rate of patients is 60-90\%. As type II gastric NETs lead to the Zollinger-Ellison syndrome, the gastric $\mathrm{pH}$ on endoscopy is typically very low, due to high acidity levels.

\section{Type 3 gastric NET}

Type 3 gastric NETs are sporadic tumours of no specific etiology (such as atrophic inflammation or MEN1). These solitary tumours with normogastrinemia have the worst prognosis of all three ECL cell NETs (50\% metastasize). The 5-year survival rate of patients does not exceed 50\% [28-30].

Gastric NENs of type 1 and type 2 are usually graded as well differentiated NETs G1 and NETs G2. Type 3 Gastric NENs are graded as NETs G3 or poorly differentiated NECs $[9,13,21,25]$. Gastric NECs and MiNENs are usually located in the antrum or in the cardiac regions [34]. Gastric NECs usually deeply infiltrate the gastric wall. Gastric NECs and MiNENs have a poor prognosis, progress rapidly and take an aggressive course [28]. The TNM classification and staging of gastric NETs are given in tables III and IV.

\section{Neuroendocrine tumours of the duodenum and the ampulla of Vater}

The 2017 AJCC staging system applies to well-differentiated neuroendocrine tumours of the duodenum and the ampulla of Vater. Carcinomas of the ampulla of Vater, including high-grade, poorly differentiated neuroendocrine carcinomas are not staged within this system and should be classified according to classical criteria applied to adenocarcinomas of organs of the digestive system. 
Table III. AJCC 2017 TNM classification for neuroendocrine tumours of the stomach $[9,11]$

\begin{tabular}{|c|c|}
\hline \multicolumn{2}{|c|}{ Definition of primary tumour $(\mathrm{T})$} \\
\hline T category & T criteria \\
\hline TX & primary tumour cannot be assessed \\
\hline T0 & no evidence of primary tumour \\
\hline $\mathrm{T} 1^{*}$ & tumour invades the lamina propria or submucosa and is less than or equal to $1 \mathrm{~cm}$ in size \\
\hline $\mathrm{T} 2^{*}$ & tumour invades the muscularis propria or is greater than $1 \mathrm{~cm}$ in size \\
\hline $\mathrm{T}^{*}$ & tumour invades through the muscularis propria into subserosal tissue without penetration of overlying serosa \\
\hline $\mathrm{T} 4^{*}$ & tumour invades visceral peritoneum (serosa) or other organs or adjacent structures \\
\hline \multicolumn{2}{|c|}{ Definition of regional lymph node (N) } \\
\hline N category & N criteria \\
\hline NX & regional lymph nodes cannot be assessed \\
\hline NO & no regional lymph node metastasis \\
\hline N1 & regional lymph node metastasis \\
\hline \multicolumn{2}{|c|}{ Definition of distant metastasis (M) } \\
\hline M category & M criteria \\
\hline M0 & no distant metastasis \\
\hline M1 & distant metastasis \\
\hline M1a & metastasis confined to liver \\
\hline $\mathrm{M} 1 \mathrm{~b}$ & metastases in at least one extrahepatic site (e.g., lung, ovary, nonregional lymph node, peritoneum, bone) \\
\hline M1C & both hepatic and extrahepatic \\
\hline
\end{tabular}

*For any $T$, add (m) for multiple tumours [TX(\#) or TX(m), where $X=1-4$ and \# = number of primary tumours identified; for multiple tumours with different Ts, use the highest

Table IV. AJCC 2017 prognostic stage groups for neuroendocrine tumours of the stomach $[9,11]$

\begin{tabular}{|lc|}
\hline TNM & Stage group \\
\hline T1 NO MO & I \\
\hline T2-T3 NO MO & $\|$ \\
\hline T4 NO MO & II \\
\hline any T N1 MO & II \\
\hline any T, any N M1 & IV \\
\hline
\end{tabular}

The following changes were introduced by the 2017 AJCC staging system: neuroendocrine tumours of the duodenum and ampulla, being different in tumour biology and prognosis, are now considered separately from those in the jejunum and ileum. The Tis (tumour in situ) distinction has now been eliminated [10, 11].

Over the years 1983-2010, the yearly incidence rate of duodenal NETs was observed to increase from 0.27 to 1.1 per 100000 individuals [36]. The duodenal NET outcome relies on the histologic grade, depth of invasion and size of the tumour [36]. Duodenal NETs (95\%) are mostly located in the first part or in the ampullary region of the duodenum. NETs arising in the ampulla of Vater are extremely rare but are often larger and of higher grade (G3), and frequently metastasize - even while being small and of low grade (G1, G2). Poorer overall survival than in the case of duodenal NETs can be expected [37]. Most duodenal NETs are below $2 \mathrm{~cm}$ in diameter, usually without lymph node involvement [38]. However, gastrinomas may metastasize, despite being very small in size $(<1 \mathrm{~cm})[36]$.
Most duodenal NETs are non-functioning. Gangliocytic paragangliomas contain NET-like elements but also show variable amounts of ganglion-like cells and spindled Schwann cells. Being indolent, they typically do not recur after resection. Gangliocytic paraganglioma and somatostatin-expressing NET occur almost exclusively in the ampullary and periampullary region [29]. Less frequent are functioning duodenal NETs - gastrinomas associated with the Zollinger-Ellison syndrome (ZES), which usually occur in the duodenum (60-80\% of cases) and pancreas. However, duodenal/ampullary NETs may produce somatostatin (about 1\% of gastrointestinal NETs), adrenocorticotropic hormone, VIP or serotonin, leading to the traditional carcinoid syndrome $[10,11,38]$.

Not much is known about the etiology of NETs of the duodenum/ampulla of Vater. Most of these NETs are sporadic, however a small fraction (below 10\%) is ascribed to hereditary cancer syndrome, such as multiple endocrine neoplasia type 1 (MEN1), neurofibromatosis type 1 (NF1) and von Hippel-Lindau (VHL) syndrome. Patients with MEN1 develop multiple duodenal gastrinomas, patients with NF1 - somatostatin expressing tumours [10, 25, 29, 39].

Most duodenal NETs are well-differentiated (G1 and G2) tumours [12]. NECs (G3 by definition) of the small bowel occur only within the ampullary region and should be staged as carcinomas in this location [37]. An adenocarcinoma component may also be present in MiNENs. The TNM classification and staging of NETs of the duodenum and ampulla of Vater are given in tables $\mathrm{V}$ and $\mathrm{VI}$. 


\section{Neuroendocrine tumours of the jejunum and ileum}

The 2017 AJCC staging system applies to neuroendocrine tumours of the jejunum and ileum. These include small bowel "carcinoid"tumours NET G1 and G2, and rare well-differentiated NET G3 arising in these locations. High-grade neuroendocrine carcinomas (NEC) and mixed adenoneuroendocrine carcinomas (MiNEN) should be classified according to classical criteria applied to the small intestine.

The following changes were introduced by the 2017 AJCC staging system: a new classification of nodal involvement, N2, is proposed; stages I-IV were condensed, i.e. substages A and $B$ were excluded; the duodenum is considered separately; neurokinin A (NKA) was added as a possible prognostic factor for clinical care [41].

Over the years 1973-2012, the yearly incidence of well-differentiated small intestinal NETs varied between 0.32 in England and 1.2 in the US, per 100000 inhabitants [42, 43]. The location of jejunoileal NETs is mainly in the distal part of the ileum, close to the ileocaecal valve. Therefore diagnostics of these NETs depends on their accessibility in routine endoscopy. About 33\% of those NETs in the small intestine are multifocal. Jejunal or ileal NETs are usually small, growing
Table VI. AJCC 2017 prognostic stage groups for neuroendocrine tumours of the duodenum and the ampulla of Vater $[10,11]$

\begin{tabular}{|lc|}
\hline TNM & Stage group \\
\hline T1 NO MO & । \\
\hline T2-T3 NO MO & ॥ \\
\hline T4 NO MO & III \\
\hline any TN1 MO & III \\
\hline any T, any NM1 & IV \\
\hline
\end{tabular}

at a slower rate than adenocarcinoma, but disseminating to the locoregional lymph node and liver [43-45]. Due to the absence of clinical symptoms, diagnosis is typically delayed until the tumour has metastasized to the liver $[16,40]$. However, despite this advanced presentation, the prognosis for patients is reasonably favourable. A higher risk of long-term recurrence is suggested in patients with nodal metastases, mesenteric involvement and lymphovascular or perineural invasion $[42,43,45,46]$

Intestinal NENs are either functioning or non-functioning NETs. Functioning NETs are mostly composed of enterochro-

Table V. AJCC 2017 TNM classifications for neuroendocrine tumours of the duodenum and the ampulla of Vater $[10,11]$

\begin{tabular}{|c|c|}
\hline \multicolumn{2}{|c|}{ Definition of primary tumour $(\mathrm{T})$} \\
\hline T category & T criteria \\
\hline TX & primary tumour cannot be assessed \\
\hline T1 & $\begin{array}{l}\text { tumour invades the mucosa or submucosa only and is } \leq 1 \mathrm{~cm} \text { (duodenal tumours); tumour } \leq 1 \mathrm{~cm} \text { and confined within the sphincter } \\
\text { of Oddi (ampullary tumours) }\end{array}$ \\
\hline $\mathrm{T} 2$ & tumour invades the muscularis propria or is $>1 \mathrm{~cm}$ (duodenal); \\
\hline & tumour invades through the sphincter into the duodenal submucosa or muscularis propria, or is $>1 \mathrm{~cm}$ (ampullary) \\
\hline T3 & tumour invades the pancreas or peripancreatic adipose tissue \\
\hline T4 & tumour invades the visceral peritoneum (serosa) or other organs \\
\hline \multicolumn{2}{|c|}{ Definition of regional lymph node (N) } \\
\hline N category & N criteria \\
\hline NX & regional lymph nodes cannot be assessed \\
\hline No & no regional lymph node involvement \\
\hline N1 & regional lymph node involvement \\
\hline \multicolumn{2}{|c|}{ Definition of distant metastasis (M) } \\
\hline M category & M criteria \\
\hline MO & no distant metastasis \\
\hline M1 & distant metastases \\
\hline M1a & metastasis confined to liver \\
\hline M1b & metastases in at least one extrahepatic site (e.g., lung, ovary, nonregional lymph node, peritoneum, bone) \\
\hline M1c & both hepatic and extrahepatic metastases \\
\hline
\end{tabular}

Multiple tumours should be designated as such (and the largest tumour should be used to assign the T category): 1) If the number of tumours is known, use T(\#); e.g., pT3(4)NOM0; 2) If the number of tumours is unavailable or too numerous, use the suffix $m-T(m)-$ e.g., pT3(m)NOMO 
Table VII. AJCC 2017 TNM classification for neuroendocrine tumours of the jejunum and ileum [11, 22]

\begin{tabular}{|c|c|}
\hline \multicolumn{2}{|c|}{ Definition of primary tumour $(\mathrm{T})$} \\
\hline T category & T criteria \\
\hline TX & primary tumour cannot be assessed \\
\hline T0 & no evidence of primary tumour \\
\hline $\mathrm{T} 1^{*}$ & tumour invades lamina propria or submucosa and is less than or equal to $1 \mathrm{~cm}$ in size \\
\hline $\mathrm{T} 2^{*}$ & tumour invades the muscularis propria or is greater than $1 \mathrm{~cm}$ in size \\
\hline $\mathrm{T}^{*}$ & tumour invades through the muscularis propria into subserosa tissue without penetration of overlying serosa \\
\hline $\mathrm{T} 4^{*}$ & tumour invades the visceral peritoneum (serosal) or other organs or adjacent structures \\
\hline \multicolumn{2}{|c|}{ Definition of regional lymph node (N) } \\
\hline N category & N criteria \\
\hline NX & regional lymph nodes cannot be assessed \\
\hline NO & no regional lymph node metastasis has occurred \\
\hline N1 & regional lymph node metastasis less than 12 nodes \\
\hline N2 & $\begin{array}{l}\text { large mesenteric masses ( }>2 \mathrm{~cm} \text { ) and/or extensive nodal deposits (12 or greater), especially those that encase the } \\
\text { superior mesenteric vessels }\end{array}$ \\
\hline \multicolumn{2}{|c|}{ Definition of distant metastasis (M) } \\
\hline M category & M criteria \\
\hline MO & no distant metastasis \\
\hline M1 & distant metastasis \\
\hline M1a & metastasis confined to liver \\
\hline $\mathrm{M} 1 \mathrm{~b}$ & metastases in at least one extrahepatic site (e.g., lung, ovary, nonregional lymph node, peritoneum, bone) \\
\hline M1c & both hepatic and extrahepatic metastases \\
\hline
\end{tabular}

*For any $T$, add (m) for multiple tumours [TX(\#) or TX(m), where $X=1-4$, and \# = number of primary tumours identified; for multiple tumours with different $T$, use the highest

maffin (EC) cells secreting serotonin or other peptides. In Europe, the term carcinoid is used to represent a midgut-originating tumour, secreting serotonin and associated with the carcinoid syndrome. The 2019 WHO classification only distinguishes between well-differentiated NETs G1, G2, G3 and poorly differentiated NECs in all sites where they occur.

In the case of functioning NETs, 30\% of patients present with hormone-induced symptoms (flushing, sweating, diarrhoea, wheezing), called "carcinoid syndrome" which are difficult to control $[47,48]$. Factors causing fibrosis (5-HT, tissue growth factors, tachy- and bradykinins) may also induce right-sided cardiac valve damage (carcinoid heart disease or Hedinger syndrome) $[16,47]$.

Hormonally non-functioning NENs of the small intestine, usually asymptomatic, are found accidentally during colonoscopy in the ileocaecal region or when looking for the primary tumour in patients with metastases. Tumours, of over $1 \mathrm{~cm}$ diameter, are often malignant and metastatic $[16,22,40]$.

Most NENs of the small intestine are well-differentiated NET G1 and NET G2, with a reasonably good 5-year prognosis $[16,40]$. Well-differentiated NET G3 are rare, presenting as well-differentiated neoplasms, unlike poorly differentiated NECs. They are located almost exclusively in the ampullary region and should be staged according to carcinomas arising in this location [37]. The TNM classification and staging of NETs of the jejunum and ileum are given in tables VII and VIII.

\section{Neuroendocrine tumours of the appendix}

The 2017 AJCC staging system applies to neuroendocrine tumours of the appendix. These include appendiceal NETs (carcinoid) tumours (NET G1 and G2, and rare well-differentiated NET G3). High-grade neuroendocrine carcinomas (NEC), goblet cell carcinoids, mixed adenocarcinomas and adenocarcinomas should be staged according to the classification for appendix carcinomas. The following changes were introduced by the 2017 AJCC staging system: stages I-IV were condensed, i.e. substages A and B were excluded.

Appendiceal NETs similarly to jejunoileal midgut NETs, used to be called appendiceal carcinoids. However, within the current 2017 AJCC staging system, they are now classified separately from jejunoileal NETs due to behavio-

Table VIII. AJCC 2017 prognostic stage groups for neuroendocrine tumours of the jejunum and ileum [11,22]

\begin{tabular}{|lc|}
\hline TNM & Stage group \\
\hline T1 NO MO & । \\
\hline T2-T3 NO MO & $\|$ \\
\hline T4 NO MO & II \\
\hline T1-T4 N1, N2 MO & II \\
\hline any T, any N M1 & IV \\
\hline
\end{tabular}


Table IX. AJCC 2017 TNM classification for neuroendocrine tumours of the appendix [11,23]

\begin{tabular}{|c|c|}
\hline \multicolumn{2}{|c|}{ Definition of primary tumour $(\mathrm{T})$} \\
\hline T category & T criteria \\
\hline TX & primary tumour cannot be assessed \\
\hline T0 & no evidence of primary tumour \\
\hline T1 & tumour is $2 \mathrm{~cm}$ or less in greatest dimension \\
\hline $\mathrm{T} 2$ & tumour is more than $2 \mathrm{~cm}$ but less than or equal to $4 \mathrm{~cm}$ \\
\hline T3 & tumour is more than $4 \mathrm{~cm}$ or with subserosal invasion or involvement of the mesoappendix \\
\hline T4 & $\begin{array}{l}\text { tumour perforates the peritoneum or directly invades other adjacent organs or structures (excluding direct mural } \\
\text { extension to adjacent subserosa of adjacent bowel), e.g., abdominal wall and skeletal muscle }\end{array}$ \\
\hline \multicolumn{2}{|c|}{ Definition of regional lymph node (N) } \\
\hline N category & N criteria \\
\hline NX & regional lymph nodes cannot be assessed \\
\hline No & no regional lymph node metastasis \\
\hline N1 & regional lymph node metastasis \\
\hline \multicolumn{2}{|c|}{ Definition of distant metastasis (M) } \\
\hline M category & M criteria \\
\hline MO & no distant metastasis \\
\hline M1 & distant metastasis \\
\hline M1a & metastasis confined to liver \\
\hline M1b & metastases in at least one extrahepatic site (e.g., lung, ovary, nonregional lymph node, peritoneum, bone) \\
\hline M1C & both hepatic and extrahepatic metastases \\
\hline
\end{tabular}

ural differences and higher incidence [12]. Over the years 1973-2012, according to the SEER database, the yearly incidence of appendiceal NETs was 0.2 per 100000 individuals $[23,43]$. Of all appendiceal neoplasms, typically arising in the tip of the appendix and discovered accidentally at appendectomy [50], appendiceal NETs are the most frequent (up to $85 \%$ ) [23].

Most NETs of the appendix are smaller than $1 \mathrm{~cm}$ in diameter. Major criteria of potential aggressiveness are the tumour size and infiltration of the mesoappendix. Appendiceal NETs have an excellent prognosis. With tumours smaller than $1 \mathrm{~cm}$ in diameter, metastases occur only in some $2 \%$ of cases [ 40 , $49,51]$. In patients with appendiceal NETs without lymph node metastases, the 10-year survival rate ranges between 90-100\% $[43,51]$. Appendiceal NENs are graded as well - differentiated NETs G1 and G2. Appendiceal NECs are morphologically similar to colonic counterparts. They are rare and may occur in any part of the appendix [13].

Goblet cell carcinoids are now termed goblet cell adenocarcinomas, as neuroendocrine cells are their minor component, while mucin-secreting cells are their major element. MiNENs of the appendix are also rare and may display a combination of NEC and adenocarcinoma, as do colonic MiNENs. The term mixed adenoneuroendocrine carcinoma (MANEC) is no longer used. The TNM classification and staging of NETS of the appendix are given in tables IX and $X$.

\section{Neuroendocrine tumours of the colon and rectum}

The 2017 AJCC staging system applies to neuroendocrine tumours of the colon and rectum. These include colonic and rectal "carcinoid" tumours (neuroendocrine tumour G1 and G2, and rare well-differentiated NET G3). High-grade neuroendocrine carcinomas and mixed adenoneuroendocrine carcinomas should be staged according to the classification of colon and rectum carcinomas. Against the 2010 Seventh Edition, no changes were introduced in the 2017 Eight Edition of AJCC [13].

The yearly incidence of colonic and rectal NENs is rising and estimated at 0.2 and 1.2 new cases per 100000 individuals, respectively [53]. Colorectal NENs are usually silent or associated with mass-related nonspecific symptoms, such as pain, haemorrhage or constipation.

Table X. AJCC 2017 prognostic stage groups for neuroendocrine tumours of the appendix $[11,23]$

\begin{tabular}{|lc|}
\hline TNM & Stage group \\
\hline T1 NO MO & I \\
\hline T2-T3 NO MO & I \\
\hline T4 NO MO & III \\
\hline any T N1 MO & III \\
\hline any T, any NM1 & IV \\
\hline
\end{tabular}


Colonic and rectal NENs differ significantly [2]. Colonic NETs are rare tumours, typically larger than their rectal counterparts, are more aggressive, poorly differentiated and of histologically higher grade G3 [2]. Rectal NETs tend to be smaller, over 50\% being below $1 \mathrm{~cm}$ in diameter in younger patients and are of low or intermediate grade G1/G2 [54].

Colonic NETs have the worst prognosis among gastrointestinal (GI) NETs - about $67 \%$ of patients have a 5 -year survival rate, while for rectal NETs the 5-year survival rate is about 96\%[55]. Apparently, NETs originating from the midgut and the hindgut exhibit different clinicopathological features [56].

On diagnosis, colorectal NECs and MiNENs may be widely disseminated. MiNENs of the colorectum contain a poorly differentiated neuroendocrine and an adenocarcinoma component. Occasionally, in patients with idiopathic inflammatory diseases, MiNENs with a low-grade NET component may occur [57]. The TNM classification and staging of NETs of the colon and rectum are given in tables XI and XII.

\section{Neuroendocrine tumours of the pancreas}

The 2017 AJCC staging system applies to well-differentiated neuroendocrine tumours arising in the pancreas. Carcinomas of the pancreas, including high-grade (G3) and poorly differentiated neuroendocrine carcinomas, should be staged according to the classification for exocrine pancreas carcinomas.

The following changes were introduced by the 2017 AJCC staging system: pancreatic neuroendocrine tumours are now staged using a TNM staging system based on size; the criterion of peripancreatic soft tissue invasion was eliminated; the Tis distinction was eliminated; $\mathrm{M} 1$ is subdivided into $\mathrm{M} 1 \mathrm{a}$ - metastases confined to the liver, M1 b - metastases in at least one extrahepatic site (e.g. lung, ovaries, nonregional lymph nodes, peritoneum, bones) and M1c - both hepatic and extrahepatic metastases. In the AJCC Cancer Staging Manual, the $8^{\text {th }}$ Edition staging system has been modified to be consistent with the ENETS system [58,60].

Pancreatic neuroendocrine neoplasms (pNENs) occur in $2-5 \%$ of all pancreatic tumours [61]. Due to improvements in imaging, the yearly worldwide incidence of pancreatic neuroendocrine tumours (pNETs) has rapidly increased to $2.5-5$ per 100

Table XI. AJCC 2017 TNM classification for neuroendocrine tumours of the colon and rectum [11, 24]

\begin{tabular}{|c|c|}
\hline \multicolumn{2}{|c|}{ Definition of primary tumour (T) } \\
\hline T category & T criteria \\
\hline TX & primary tumour cannot be assessed \\
\hline TO & no evidence of primary tumour \\
\hline $\mathrm{T} 1$ & tumour invades the lamina propria or submucosa and is $\leq 2 \mathrm{~cm}$ \\
\hline T1a & tumour is $<1 \mathrm{~cm}$ in greatest dimension \\
\hline $\mathrm{T} 1 \mathrm{~b}$ & tumour is $1-2 \mathrm{~cm}$ in greatest dimension \\
\hline $\mathrm{T} 2$ & tumour invades the muscularis propria or is $>2 \mathrm{~cm}$ with invasion of the lamina propria or submucosa \\
\hline T3 & tumour invades through the muscularis propria into the subserosal tissue without penetration of overlying serosa \\
\hline T4 & tumour invades the visceral peritoneum (serosa) or other organs or adjacent structures \\
\hline \multicolumn{2}{|c|}{ Definition of regional lymph node $(\mathrm{N})$} \\
\hline N category & N criteria \\
\hline NX & regional lymph nodes cannot be assessed \\
\hline No & no regional lymph node metastasis has occurred \\
\hline N1 & regional lymph node metastasis \\
\hline \multicolumn{2}{|c|}{ Definition of distant metastasis (M) } \\
\hline M category & M criteria \\
\hline MO & no distant metastasis \\
\hline M1 & distant metastasis \\
\hline M1a & metastasis confined to liver \\
\hline $\mathrm{M} 1 \mathrm{~b}$ & metastases in at least one extrahepatic site (e.g., lung, ovary, nonregional lymph node, peritoneum, bone) \\
\hline M1c & both hepatic and extrahepatic metastases \\
\hline
\end{tabular}

For multiple synchronous tumours, the highest T category should be used and the multiplicity or the number of tumours should be indicated in parenthesis, e.g., $T 3(2)$ or T3(m) 
Table XII. AJCC 2017 prognostic stage groups for neuroendocrine tumours of the colon and rectum $[11,24]$

\begin{tabular}{|lc|}
\hline TNM & Stage group \\
\hline T1 NO MO & । \\
\hline T2 NO MO & IA \\
\hline T3 NO MO & IB \\
\hline T4 NO MO & IIA \\
\hline any T N1 MO & IIB \\
\hline any T, any N M1 & N \\
\hline
\end{tabular}

000 individuals [62-63]. ENETS developed the grading classification system for pancreatic NETs adopted by theWHO in 2010 [15, 64] and updated in 2017 by AJCC $[8,21,65,66]$. A new group of well differentiated high grade $\mathrm{G} 3$ tumours of the pancreas with favourable prognosis, compared with poorly differentiated NEC, was introduced [67]. The new category of well differentiated G3 pNETs show intact TP53 and RB1 in primary G3 pNETs [26]. G3 pancreatic NETs may contain low-grade components. Grade is a significant predictor of outcome in pancreatic NETs [17, 21, $25,58,65,66,68]$. While pNECs grow rapidly and have a poor prognosis, the survival rate for slow-growing pNETs is better [69].

Clinically, pNENs may be categorised as functional (F-pNET) or non-functional (NF-pNET) tumours. Up to 20\% of pNETs are responsible for specific clinical syndromes due to hormone excess. These F-pNETs, located mostly in the tail of the pancreas, include gastrinomas, insulinomas, VIPomas, glucagonomas and, less common tumours secreting $\mathrm{ACTH}$, PTHrP, CCK, GHRH and serotonin (tab. XIII).

In cases where expression of various hormones by immunohistochemistry does not correlate with secretion, these tumours are termed non-functional pancreatic NETs (NF-pNETs) [70]. However, NF-pNETs do secrete several substances into the serum, including chromogranin A (CgA), pancreatic polypeptide (PP), pancreastatin, and neuron-specific enolase, some of which are used as markers of NENs [70]. Most NF-pNETs, occurring at least twice as frequently as F-pNETs, are located in the head of the pancreas $[8,21]$.

In the $5^{\text {th }}$ edition of the WHO classification, mixed neuroendocrine neoplasms of the pancreas, previously termed mixed adenoneuroendocrine carcinomas (MANEC), are now termed mixed neuroendocrine- non-neuroendocrine neoplasms (MiNEN) [13]. Following the 2017 WHO classification update, the term hyperplastic and preneoplastic lesions, described only in some hereditary cancer syndromes such as MEN1 or VHL (von Hippel-Lindau syndrome), are no longer in use [71].

The etiology of pancreatic NETs is unknown. Most pancreatic NETs are sporadic, harbouring somatic mutations (43\% DAXX/ATRX mutations, 44\% MEN1 mutations or mutations of mTOR pathway genes) [52]. Less than $10 \%$ of all pancreatic NETs are part of the hereditary cancer syndrome [1]. Multiple endocrine neoplasia type 1 (MEN1) is the most common. Less common are: von Hippel-Lindau disease (mutation in the VHL gene), Neurofibromatosis type 1 (mutation in Nf1). Quite rare are the Tuberous sclerosis complex (mutation in TSC1 or TSC2) or Mahvash disease (pancreatic NET caused by inactivating glucagon receptor mutation) [59]. The TNM classification and staging of NETs of the pancreas is given in table XIV and table XV.

\section{Proposal of new classification framework}

In 2018 the International Agency for Research on Cancer of the World Health Organization (IARC-WHO) proposed a new framework for general classification of neuroendocrine neoplasia in all organs [8]. The currently applied NEN definitions which may complicate patient evaluation and treatment, are predominantly organ-based rather than ordered by similarity in their genetic origin, morphology or clinical behaviour, as recognised by recent advances in these disciplines. Thus, in the new proposal, the neuroendocrine phenotype is a unique cancer category, now recommended as a neuroendocrine neoplasm, NEN, for all organs. Rindi and Inzani propose [72] that in this cancer category two classes be distinguished: a well differentiated neoplasm is defined as a neuroendocrine tumour (NET) while a poorly differentiated neoplasm - as a neuroendocrine carcinoma (NEC), in all anatomical sites. NETs are further graded according to their proliferation into G1, G2 and G3, while NEC are G3 only, by definition. Within the NEC class, small cell and large cell types are distinguished.

As described above, organ-specific grading (G) cut-offs are known for the digestive system (and also for the lung), however, such cut-offs for other organs remain to be established. It is suggested that current pathology reports contain the above-discussed newly recommended classification together with the currently observed classification. To provide an example, the new classification of NENs of the gut and pancreas is given in table XVI.

Table XIII. Characteristics of functional pancreatic neuroendocrine tumours [58]

\begin{tabular}{lll}
\hline Name & Neurohormone secreted & Common symptoms \\
\hline insulinoma & insulin & hypoglycemic symptoms, Whipple's triad \\
\hline gastrinoma & gastrin & abdominal pain, gastroesophageal reflux, diarrhoea, duodenal and stomach ulcers \\
\hline VIPoma & $\begin{array}{l}\text { vasoactive intestinal } \\
\text { peptide (VIP) }\end{array}$ & diarrhoea, hypokalemia, dehydration, muscle weakness, nausea \\
\hline glucagonoma & glucagon & rash, glucose intolerance, weight loss, erythematous lesions over the distal extremities \\
\hline somatostatinoma & somatostatin & diabetes mellitus, cholelithiasis, diarrhoea \\
\hline ACTHoma & ACTH & Cushing's syndrome \\
\hline
\end{tabular}


Table XIV. A JCC 2017 TNM classification for neuroendocrine tumours of the pancreas [11, 58]

\begin{tabular}{|c|c|}
\hline \multicolumn{2}{|c|}{ Definition of primary tumour (T) } \\
\hline T category & T criteria \\
\hline TX & tumour cannot be assessed \\
\hline T1 & tumour limited to the pancreas, ${ }^{*}<2 \mathrm{~cm}$ \\
\hline $\mathrm{T} 2$ & tumour limited to the pancreas, ${ }^{*} 2-4 \mathrm{~cm}$ \\
\hline T3 & tumour limited to the pancreas, ${ }^{*}>4 \mathrm{~cm}$; or tumour invading the duodenum or common bile duct \\
\hline T4 & $\begin{array}{l}\text { tumour invading adjacent organs (stomach, spleen, colon, adrenal gland) or the wall of large vessels (celiac axis or } \\
\text { the superior mesenteric artery) }\end{array}$ \\
\hline \multicolumn{2}{|c|}{ Definition of regional lymph node (N) } \\
\hline N category & N criteria \\
\hline NX & regional lymph nodes cannot be assessed \\
\hline No & no regional lymph node involvement \\
\hline N1 & regional lymph node involvement \\
\hline \multicolumn{2}{|c|}{ Definition of distant metastasis (M) } \\
\hline M category & M criteria \\
\hline M0 & no distant metastasis \\
\hline M1 & distant metastases \\
\hline M1a & metastasis confined to liver \\
\hline M1b & metastases in at least one extrahepatic site (e.g., lung, ovary, nonregional lymph node, peritoneum, bone) \\
\hline M1c & both hepatic and extrahepatic metastases \\
\hline
\end{tabular}

Table XV. AJCC 2017 prognostic stage groups for neuroendocrine tumours of the pancreas $[11,58]$

\begin{tabular}{|lc|}
\hline TNM & Stage group \\
\hline T1 N0 MO & । \\
\hline T2-T3 N0 M0 & ॥ \\
\hline T4 N0 MO & III \\
\hline any T N1 MO & III \\
\hline any T, any N M1 & IV \\
\hline
\end{tabular}

Conflict of interest: none declared

\section{Agata Bałdys-Waligórska}

Andrzej Frycz Modrzewski Krakow University

Faculty of Medicine and Health Sciences

Chair of Endocrinology and Internal Diseases, Faculty of Medicine and Health Sciences

ul. G. Herlinga-Grudzińskiego 1

30-705 Kraków, Poland

e-mail:awalig@cm-uj.krakow.pl

Received and accepted: 13 Oct 2020

Table XVI. The new framework proposed for general classification of neuroendocrine neoplasia (NEN) in all organs $[8,72]$

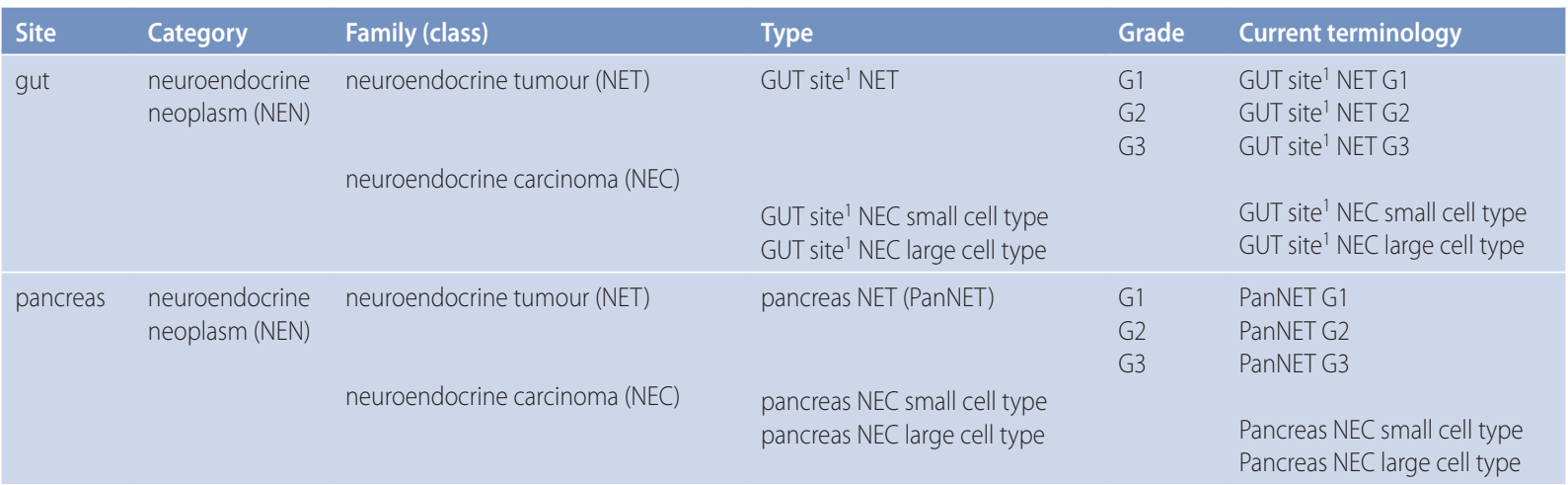

${ }^{1}$ Site stands for the adjective connoting the different districts of the tubular gut where the NEN develops, that is, oesophageal, gastric, duodenal, small intestinal, appendiceal, colonic, rectal and anal canal NET or NEC. 


\section{References}

1. Yao J, Hassan M, Phan A, et al. One Hundred Years After "Carcinoid": Epidemiology of and Prognostic Factors for Neuroendocrine Tumors in 35,825 Cases in the United States. J Clin Oncol. 2008; 26(18): 3063-3072, doi: 10.1200/jco.2007.15.4377.

2. Ramage JK, De Herder WW, Delle Fave G, et al. Vienna Consensus Conference participants. ENETS Consensus Guidelines Update for Colorectal Neuroendocrine Neoplasms. Neuroendocrinology. 2016; 103(2): 139-143, doi: 10.1159/000443166, indexed in Pubmed: 26730835.

3. Kos-Kudła B, Blicharz-Dorniak J, Strzelczyk J, et al. Consensus Conference, Polish Network of Neuroendocrine Tumours, oraz Pozostali Uczestnicy Konferencji Okragłego Stołu. [Diagnostic and therapeutic guidelines for gastrointestinal neuroendocrine tumors (recommended by the Polish Network of Neuroendocrine Tumors)]. Endokrynol Pol. 2008; 59(1): 41-56, indexed in Pubmed: 18335400.

4. Fawcett D. Bloom \& Fawcett concise histology. 2nd ed. Chapman \& Hall, New York 2002.

5. Pape UF, Perren A, Niederle B, et al. Barcelona Consensus Conference participants. ENETS Consensus Guidelines for the management of patients with neuroendocrine neoplasms from the jejuno-ileum and the appendix including goblet cell carcinomas. Neuroendocrinology. 2012; 95(2): 135-156, doi: 10.1159/000335629, indexed in Pubmed: 22262080.

6. Rindi G, Klöppel G, Alhman H, et al. all other Frascati Consensus Conference participants, European Neuroendocrine Tumor Society (ENETS). TNM staging of foregut (neuro)endocrine tumors: a consensus proposal including a grading system. Virchows Arch. 2006; 449(4): 395-401, doi: 10.1007/s00428-006-0250-1, indexed in Pubmed: 16967267.

7. Milione M, Maisonneuve P, Spada F, et al. The Clinicopathologic Heterogeneity of Grade 3 Gastroenteropancreatic Neuroendocrine Neoplasms: Morphological Differentiation and Proliferation Identify Different Prognostic Categories. Neuroendocrinology. 2017; 104(1): 85-93, doi: 10.1159/000445165, indexed in Pubmed: 26943788.

8. Rindi G, Klimstra DS, Abedi-Ardekani B, et al. A common classification framework for neuroendocrine neoplasms: an International Agency for Research on Cancer (IARC) and World Health Organization (WHO) expert consensus proposal. Mod Pathol. 2018; 31(12): 1770-1786, doi: 10.1038/s41379-018-0110-y, indexed in Pubmed: 30140036.

9. Woltering EA, Bergsland EK, Beyer DT, et al. Neuroendocrine Tumors of the Stomach. American Joint Committee on Cancer 2017. In: Amin $M B$, et al. ed. AJCC Cancer Staging Manual. Eight Edition. Springer 2017: 351-359.

10. Bergsland EK, Woltering EA, Rindi G, et al. Neuroendocrine Tumors of the Duodenum and Ampulla of Vater. American Joint Committee on Cancer 2017. In: Amin MB, et al. ed. AJCC Cancer Staging Manual. Eight Edition. Springer 2017: 361-373.

11. Asare E, Bergsland EK, Brierley J, et al. Part VI Neuroendocrine tumors. In: Amin MB, et al. ed. AJCC Cancer Staging Manual, 8th edition. American College of Surgeons, Chicago 2018: 351-419.

12. Rindi G, Klöppel G, Alhman H, et al. all other Frascati Consensus Conference participants, European Neuroendocrine Tumor Society (ENETS). TNM staging of foregut (neuro)endocrine tumors: a consensus proposal including a grading system. Virchows Arch. 2006; 449(4): 395-401, doi: 10.1007/s00428-006-0250-1, indexed in Pubmed: 16967267.

13. WHO Classification of Tumours Editorial Board 2019, WHO Classification of Tumours 5th Edition. Digestive System Tumours. IARC Press, Lyon .

14. Klimstra DS, Modlin IR, Coppola D, et al. The pathologic classification of neuroendocrine tumors: a review of nomenclature, grading, and staging systems. Pancreas. 2010; 39(6): 707-712, doi: 10.1097/MPA .0b013e3181ec124e, indexed in Pubmed: 20664470.

15. Bosman FT, Carneiro F, Hruban RH. eds. WHO classification of tumours of the digestive system, 4th ed. International Agency for Research on Cancer, Lyon 2010: vol. 3: 13-14.

16. Niederle B, Pape UF, Costa F, et al. Vienna Consensus Conference participants. ENETS Consensus Guidelines Update for Neuroendocrine Neoplasms of the Jejunum and Ileum. Neuroendocrinology. 2016; 103(2): 125-138, doi: 10.1159/000443170, indexed in Pubmed: 26758972.

17. Falconi M, Eriksson B, Kaltsas G, et al. ENETS Consensus Guidelines Update for the Management of Patients with Functional Pancreatic Neuroendocrine Tumors and Non-Functional Pancreatic Neuroendocrine Tumors. Neuroendocrinology. 2016; 103(2): 153-171, doi: 10.1159/000443171.

18. Zandee WT, de Herder WW. The Evolution of Neuroendocrine Tumor Treatment Reflected by ENETS Guidelines. Neuroendocrinology. 2018; 106(4): 357-365, doi: 10.1159/000486096, indexed in Pubmed: 29320780.
19. Crippa S, Partelli S, Belfiori G, et al. Management of neuroendocrine carcinomas of the pancreas (WHO G3): A tailored approach between proliferation and morphology. World J Gastroenterol. 2016; 22(45): 9944-9953, doi: 10.3748/wjg.v22.i45.9944, indexed in Pubmed: 28018101.

20. Nagtegaal ID, Odze RD, Klimstra D, et al.WHO Classification of Tumours Editorial Board. The 2019WHO classification of tumours of the digestive system. Histopathology. 2020; 76(2): 182-188, doi: 10.1111/his.13975, indexed in Pubmed: 31433515.

21. WHO Classification of Tumours Editorial Board 2017. WHO Classification of Tumours. Digestive System Tumours. IARC Press, Lyon .

22. Woltering EA, Bergsland EK, Beyer DT, et al. Neuroendocrine Tumors of the Jejunum and Ileum. American Joint Committee on Cancer 2017. In: Amin MB, et al. ed. AJCC Cancer Staging Manual. Eight Edition. Springer 2017: 375-387.

23. Woltering EA, Bergsland EK, Beyer DT, et al. Neuroendocrine Tumors of the Appendix. American Joint Committee on Cancer 2017. In: Amin $\mathrm{MB}$, et al. ed. AJCC Cancer Staging Manual. Eight Edition. Springer 2017: 389-394.

24. Shi Ch, Woltering E, Deyer DT, et al. Neuroendocrine Tumors of the Colon and Rectum. American Joint Committee on Cancer 2017. In: Amin Ch, Woltering E, Deyer DT. ed. AJCC Cancer Staging Manual. Eight Edition. Springer 2017: 395-406.

25. Assarzadegan N, Montgomery E. What is New in 2019 World Health Organization (WHO) Classification of Tumors of the Digestive System: Review of Selected Updates on Neuroendocrine Neoplasms, Appendiceal Tumors, and MolecularTesting. Arch Pathol Lab Med. 2020 [Epub ahead of print], doi: 10.5858/arpa.2019-0665-RA, indexed in Pubmed: 32233993.

26. Scarpa A, Chang DK, Nones K, et al. Australian Pancreatic Cancer Genome Initiative, Australian Pancreatic Cancer Genome Initiative. Whole-genome landscape of pancreatic neuroendocrine tumours. Nature. 2017; 543(7643): 65-71, doi: 10.1038/nature21063, indexed in Pubmed: 28199314.

27. Yang Z, Wang W, Lu J, et al. Gastric Neuroendocrine Tumors (G-Nets): Incidence, Prognosis and Recent Trend Toward Improved Survival. Cell Physiol Biochem. 2018; 45(1): 389-396, doi: 10.1159/000486915, indexed in Pubmed: 29402806.

28. Li TT, Qiu F, Qian ZR, et al. Classification, clinicopathologic features and treatment of gastric neuroendocrine tumors. World J Gastroenterol. 2014; 20(1): 118-125, doi: 10.3748/wjg.v20.i1.118, indexed in Pubmed: 24415864.

29. Lipiński M, Rydzewska G, Foltyn W, et al. Gastroduodenal neuroendocrine neoplasms, including gastrinoma - management guidelines (recommended by the Polish Network of Neuroendocrine Tumours). Endokrynol Pol. 2017; 68(2): 138-153, doi: 10.5603/EP.2017.0016, indexed in Pubmed: 28540972.

30. Delle Fave G, O'Toole D, Sundin A, et al. Vienna Consensus Conference participants. ENETS Consensus Guidelines Update for Gastroduodenal Neuroendocrine Neoplasms. Neuroendocrinology. 2016; 103(2): 119-124, doi: 10.1159/000443168, indexed in Pubmed: 26784901.

31. Modlin IM, Latich I, Zikusoka M, et al. Gastrointestinal carcinoids: the evolution of diagnostic strategies. J Clin Gastroenterol. 2006; 40(7): 572-582, doi: 10.1097/00004836-200608000-00003, indexed in Pubmed: 16917396.

32. Raines $D, C$ hester $M$, Diebold $A E$, et al. A prospective evaluation of the effect of chronic proton pump inhibitor use on plasma biomarker levels in humans. Pancreas. 2012; 41(4): 508-511, doi: 10.1097/MPA.0b013e$318243 a 0 b 6$, indexed in Pubmed: 22460728.

33. Massironi S, Rossi RE, Casazza G, et al. Chromogranin A in diagnosing and monitoring patients with gastroenteropancreatic neuroendocrine neoplasms: a large series from a single institution. Neuroendocrinology. 2014; 100(2-3): 240-249, doi: 10.1159/000369818, indexed in Pubmed: 25428270.

34. La Rosa S, Vanoli A, La Rosa S, et al. Gastric neuroendocrine neoplasms and related precursor lesions. J Clin Pathol. 2014; 67(11): 938-948, doi: 10.1136/jclinpath-2014-202515, indexed in Pubmed: 25053544.

35. Brierley JD, Gospodarowicz MK, Wittekind C, et al. eds UICC TNM Classification of Malignant Tumours. Eight Edition. Wiley Blackwell 2017: 99-101.

36. Kachare SD, Liner KR, Vohra NA, et al. A modified duodenal neuroendocrine tumor staging schema better defines the risk of lymph node metastasis and disease-free survival. Am Surg. 2014; 80(8): 821-826, indexed in Pubmed: 25105406.

37. Randle RW, Ahmed S, Newman NA, et al. Clinical outcomes for neuroendocrine tumors of the duodenum and ampulla of Vater: a population- 
-based study. J Gastrointest Surg. 2014; 18(2): 354-362, doi: 10.1007/ s11605-013-2365-4, indexed in Pubmed: 24114680.

38. Hoffmann KM, Furukawa M, Jensen RT. Duodenal neuroendocrine tumors: Classification, functional syndromes, diagnosis and medical treatment. Best Pract Res Clin Gastroenterol. 2005; 19(5): 675-697, doi: 10.1016/j.bpg.2005.05.009, indexed in Pubmed: 16253893.

39. O'Shea T, Druce M. When should genetic testing be performed in patients with neuroendocrine tumours? Rev Endocr Metab Disord. 2017; 18(4): 499-515, doi: 10.1007/s11154-017-9430-3, indexed in Pubmed: 28965289.

40. Bednarczuk T, Bolanowski M, Zemczak A, et al. Nowotwory neuroendokrynne jelita cienkiego i wyrostka robaczkowego — zasady postępowania (rekomendowane przez Polską Sieć Guzów Neuroendokrynnych). Endokrynologia Polska. 2017; 68(2): 223-236, doi: 10.5603/ep.2017.0018.

41. Woltering EA, Voros BA, Thiagarajan $R$, et al. Plasma Neurokinin A Levels Predict Survival in Well-Differentiated Neuroendocrine Tumors of the Small Bowel. Pancreas. 2018; 47(7): 843-848, doi: 10.1097/ MPA.0000000000001092, indexed in Pubmed: 29939909.

42. Ellis L, Shale MJ, Coleman MP. Carcinoid tumors of the gastrointestinal tract: trends in incidence in England since 1971. Am J Gastroenterol. 2010; 105(12): 2563-2569, doi: 10.1038/ajg.2010.341, indexed in Pubmed: 20823835

43. Surveillance Epidemiology and End Results (SEER) Program (www.seer. cancer.gov) SEER*Stat Database: Incidence - SEER 9 Regs Research Data, Nov 2013 Sub (1973-2011), based on the November 2013 submission, released April 2014

44. Norlén $\mathrm{O}$, Stålberg $\mathrm{P}$, Öberg $\mathrm{K}$, et al. Long-term results of surgery for small intestinal neuroendocrine tumors at a tertiary referral center. World J Surg. 2012; 36(6): 1419-1431, doi: 10.1007/s00268-011-1296-Z, indexed in Pubmed: 21984144.

45. Frilling A, Modlin IM, Kidd M, et al. Working Group on Neuroendocrine Liver Metastases. Recommendations for management of patients with neuroendocrine liver metastases. Lancet Oncol. 2014; 15(1): e8-21, doi: 10.1016/S1470-2045(13)70362-0, indexed in Pubmed: 24384494.

46. Manguso N, Johnson J, Harit A, et al. Prognostic Factors Associated with Outcomes in Small Bowel Neuroendocrine Tumors. Am Surg. 2017; 83(10): 1174-1178, indexed in Pubmed: 29391119.

47. Grozinsky-Glasberg S, Grossman AB, Gross DJ. Carcinoid Heart Disease: From Pathophysiology to Treatment--'Something in the Way It Moves'. Neuroendocrinology. 2015; 101(4): 263-273, doi: 10.1159/000381930, indexed in Pubmed: 25871411.

48. Anthony L, Ervin C, Lapuerta P, et al. Understanding the Patient Experience with Carcinoid Syndrome: Exit Interviews from a Randomized, Placebo-controlled Study of Telotristat Ethyl. Clin Ther. 2017; 39(11): 2158-2168, doi: 10.1016/j.clinthera.2017.09.013, indexed in Pubmed: 29074312.

49. Pape UF, Niederle B, Costa F, et al. Vienna Consensus Conference participants. ENETS Consensus Guidelines for Neuroendocrine Neoplasms of the Appendix (Excluding Goblet Cell Carcinomas). Neuroendocrinology. 2016; 103(2): 144-152, doi: 10.1159/000443165, indexed in Pubmed: 26730583

50. Moris D, Tsilimigras DI, Vagios S, et al. Neuroendocrine Neoplasms of the Appendix: A Review of the Literature. Anticancer Res. 2018; 38(2):601611, doi: 10.21873/anticanres.12264, indexed in Pubmed: 29374682.

51. Mullen JT, Savarese DMF. Carcinoid tumors of the appendix: a population-based study. J Surg Oncol. 2011; 104(1): 41-44, doi: 10.1002/ jso.21888, indexed in Pubmed: 21294132.

52. StarzyńskaT, Londzin-Olesik M, Bałdys-Waligórska A, et al. Nowotwory neuroendokrynne jelita grubego - zasady postępowania (rekomendowane przez Polską Sieć Guzów Neuroendokrynnych). Endokrynologia Polska. 2017; 68(2): 250-260, doi: 10.5603/ep.2017.0019, indexed in Pubmed: 28540975.

53. Dasari A, Shen C, Halperin D, et al. Trends in the Incidence, Prevalence, and Survival Outcomes in Patients With Neuroendocrine Tumors in the United States. JAMA Oncol. 2017; 3(10): 1335-1342, doi: 10.1001/ jamaoncol.2017.0589, indexed in Pubmed: 28448665.

54. Kojima M, Ikeda K, Saito N, et al. Neuroendocrine Tumors of the Large Intestine: Clinicopathological Features and Predictive Factors of Lymph Node Metastasis. Front Oncol. 2016; 6: 173, doi: 10.3389/ fonc.2016.00173, indexed in Pubmed: 27486567.
55. Tsikitis VL, Wertheim BC, Guerrero MA. Trends of incidence and survival of gastrointestinal neuroendocrine tumors in the United States: a seer analysis. J Cancer. 2012; 3: 292-302, doi: 10.7150/jca.4502, indexed in Pubmed: 22773933.

56. Zhang Yu, Shang L, Zhang PP, et al. Clinicopathological features and prognostic validity of the European Neuroendocrine Tumor Society (ENETS) and American Joint Committee on Cancer (AJCC) 8th staging systems in colonic neuroendocrine neoplasms. Cancer Med. 2019; 8(11): 5000-5011, doi: 10.1002/cam4.2370, indexed in Pubmed: 31293053.

57. Gaspar R, Santos-Antunes J, Marques M, et al. Mixed Adenoneuroendocrine Tumor of the Rectum in an Ulcerative Colitis Patient. GE Port J Gastroenterol. 2019; 26(2): 125-127, doi: 10.1159/000489409, indexed in Pubmed: 30976618.

58. Bergsland EK, Woltering EA, Rindi G, et al. Neuroendocrine Tumors of the Pancreas. American Joint Committee on Cancer 2017. In: Amin MB, et al. ed. AJCC Cancer Staging Manual. Eight Edition. Springer 2017: 407-419.

59. Kos-Kudła B, Rosiek V, Borowska M, et al. Pancreatic neuroendocrine neoplasms - management guidelines (recommended by the Polish Network of Neuroendocrine Tumours. Endokrynol Pol. 2017; 68(2): 169-197, doi: 10.5603/EP.2017.2016, indexed in Pubmed: 28540973.

60. Li X, Gou S, Liu Z, et al. Assessment of the American Joint Commission on Cancer 8th Edition Staging System for Patients with Pancreatic Neuroendocrine Tumors: A Surveillance, Epidemiology, and End Results analysis. Cancer Med. 2018; 7(3): 626-634, doi: 10.1002/cam4.1336, indexed in Pubmed: 29380547.

61. Hill JS, McPhee JT, McDade TP, et al. Pancreatic neuroendocrine tumors: the impact of surgical resection on survival. Cancer. 2009; 115(4): 741-751, doi: 10.1002/cncr.24065, indexed in Pubmed: 19130464

62. Fitzgerald TL, Hickner ZJ, Schmitz M, et al. Changing incidence of pancreatic neoplasms: a 16-year review of statewide tumor registry. Pancreas. 2008; 37(2): 134-138, doi: 10.1097/MPA.0b013e318163a329, indexed in Pubmed: 18665072.

63. Krampitz G, Norton J. Pancreatic neuroendocrine tumors. Curr Probl Surg. 2013; 50(11): 509-545, doi: 10.1067/j.cpsurg.2013.08.001.

64. Qadan M, Ma Y, Visser BC, et al. Reassessment of the current American Joint Committee on Cancer staging system for pancreatic neuroendocrine tumors. J Am Coll Surg. 2014; 218(2): 188-195, doi: 10.1016/j. jamcollsurg.2013.11.001, indexed in Pubmed: 24321190.

65. Scoazec JY, Couvelard A. Réseau TENpath. [Classification of pancreatic neuroendocrine tumours: Changes made in the 2017 WHO classification of tumours of endocrine organs and perspectives for the future]. Ann Pathol. 2017; 37(6): 444-456, doi: 10.1016/j.annpat.2017.10.003, indexed in Pubmed: 29169836.

66. Lloyd RV, Osamura RY, Kloppel GW. WHO classification of tumours of endocrine organs. International Agency for Research on Cancer, Lyon 2010.

67. Basturk O, Yang Z, Tang LH, et al. The high-grade (WHO G3) pancreatic neuroendocrine tumor category is morphologically and biologically heterogenous and includes both well differentiated and poorly differentiated neoplasms. Am J Surg Pathol. 2015; 39(5): 683-690, doi: 10.1097/PAS.0000000000000408, indexed in Pubmed: 25723112.

68. Strosberg JR, Cheema A, Weber J, et al. Prognostic validity of a novel American Joint Committee on Cancer Staging Classification for pancreatic neuroendocrine tumors. J Clin Oncol. 2011; 29(22): 3044-3049, doi: 10.1200/JCO.2011.35.1817, indexed in Pubmed: 21709192.

69. Basturk $\mathrm{O}$, Tang $\mathrm{L}$, Hruban $\mathrm{RH}$, et al. Poorly differentiated neuroendocrine carcinomas of the pancreas: a clinicopathologic analysis of 44 cases. Am J Surg Pathol. 2014; 38(4): 437-447, doi: 10.1097/ PAS.0000000000000169, indexed in Pubmed: 24503751.

70. Klöppel G, Anlauf M. Epidemiology, tumour biology and histopathological classification of neuroendocrine tumours of the gastrointestinal tract. Best Pract Res Clin Gastroenterol. 2005; 19(4): 507-517, doi: 10.1016/j.bpg.2005.02.010, indexed in Pubmed: 16183524.

71. Esposito I, Segler A, Steiger K, et al. Pathology, genetics and precursors of human and experimental pancreatic neoplasms: An update. Pancreatology. 2015; 15(6): 598-610, doi: 10.1016/j.pan.2015.08.007, indexed in Pubmed: 26365060.

72. Rindi G, Inzani F. Neuroendocrine neoplasm update: toward universal nomenclature. Endocr Relat Cancer. 2020; 27(6): R211-R218, doi: 10.1530/ERC-20-0036, indexed in Pubmed: 32276263. 